21 Wise PJ, Neu HC. Experience with amoxicillin: an overall summary of

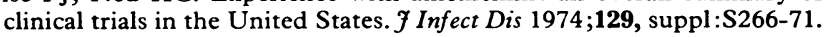

${ }^{22}$ Fang LST, Tolkoff-Rubin NE, Rubin RH. Efficacy of single-dose and conventional amoxicillin therapy in urinary-tract infection localized by the antibody-coated bacteria technic. $N$ Engl F Med 1978;298:413-6.

${ }^{23}$ Harbord RB, Grüneberg RN. Treatment of urinary tract infection with a single dose of amoxycillin, co-trimoxazole, or trimethoprim. $\mathrm{Br} \mathrm{Med} \mathrm{F}$ $1981 ; 283$ : 1301-2.

24 Leigh DA, Marriner J, Fabb S. Treatment of domiciliary urinary tract infections with a single dose of amoxycillin. F Antimicrob Chemother $1980 ; 6: 403-5$

${ }^{25}$ Cole PJ, Roberts DE, Davies SF, Knight RK. A simple oral antimicrobial regimen effective in severe chronic bronchial suppuration associated with culturable Haemophilus influenzae. $\mathcal{F}$ Antimicrob Chemother (in press).

${ }^{26}$ Shanson DC, Ashford RFU, Singh J. High-dose oral amoxycillin for preventing endocarditis. $\operatorname{Br} M e d \mathcal{F} 1980 ; 280: 446$.

\section{Writer's cramp}

Doctors' attitudes to patients suffering from the so-called occupational neuroses are exemplified by the immortal line of the doctor in Take it From Here: "There's a lot of it about but I don't know what it is!" Accordingly, we can only commend an attempt to clarify the clinical nosology of this group of functional disorders, which range from writer's cramp to the "yips" in golfers of the calibre of Sam Snead and Ben Hogan. ${ }^{1}$ A recently reported study of 29 such patients with detailed psychological evaluation in each case may not, however, have shed any further light on the nature and pathogenesis of writer's cramp in particular. Sheehy and Marsden ${ }^{2}$ have described the clinical characteristics and personality profiles of these patients dividing them into two groups, simple writer's cramp and dystonic writer's cramp (painful muscle spasms affecting manual tasks other than writing) on the basis of Gowers's original classification. ${ }^{3}$ They emphasise the low incidence of psychiatric morbidity in their patients in comparison with a control population as assessed by the present state examination and index of definition scores (developed by the Medical Research Council Social Psychiatry Unit at the Institute of Psychiatry). They also found that almost half of the patients with "simple" writer's cramp subsequently developed the dystonic form. On the basis of their data and an extensive re-examination of early published work they concluded that writer's cramp (and related occupational cramps) was a physical illness rather than a psychiatric disorder and that it represented a focal form of dystonia.

In patients with writer's cramp the posture of the affected hand is similar or even identical with that seen in torsion dystonia. ${ }^{4}$ Nevertheless, the painful muscle spasms characteristic of writer's cramp and related disorders are induced only by the movements with which they are associated, whereas dystonic posturing in torsion dystonia often develops spontaneously and is not necessarily painful. In writer's cramp spread of the painful spasms to other muscle groups is well recognised, bilateral symptoms developing not uncommonly in people who teach themselves to write with the previously unaffected hand. Several authorities have noted an association between writer's cramp and spasmodic torticollis or other forms of segmental dystonia, ${ }^{5-9}$ but there is no published evidence that writer's cramp ever evolves into generalised torsion dystonia-despite the remarkably similar abnormal posture of the hand in the two conditions, as mentioned already. Furthermore, clinical similarities do not imply identity in nosological terms or even a common pathogenesis. Torsion dystonia is an inherited disorder determined by an autosomal dominant trait in most cases, albeit with considerable variability of expression in the affected individual. ${ }^{4}$ Patients with writer's cramp occasionally give a family history suggesting that close relatives may have been affected, and Gowers lists a bewildering variety of what were almost certainly chance associations with other neurological disorders prevalent at the time and since (epilepsy, migraine, tabes dorsalis, and general paresis of the insane) ${ }^{3}$ Nevertheless, there is no clear cut evidence implicating genetic factor(s) in the aetiology of writer's cramp.

If, then, the similarities between writer's cramp and the dystonias are seen as clinical coincidence, both the aetiology and pathology of the occupational neuroses remain obscure. The second edition of Gowers's classical treatise makes it clear that he had modified his views on the nature of these disorders since the publication of the first edition six years earlier. In particular he dropped the distinction between simple and dystonic forms and in his consideration of its associations and predisposing factors made the point that "no influence is met with so frequently as to deserve special mention, except anxiety" (my italics). Further he clearly was no longer assuming the existence of a "writing centre," possibly in the cerebral cortex, as had been the case in his earlier writings. ${ }^{3}$ Accordingly he would appear to be a less than entirely reliable pillar on which to base the speculative hypothesis formulated by Sheehy and Marsden. The recent suggestion that neuronal regression in the singing centres in the male canary brain may offer a model for the loss of skills such as writing seems even more improbable. ${ }^{\text {a }}$

To turn to treatment, writer's and other occupational cramps induce in the clinician what can only be described as unrelieved gloom. Some patients are improved in the short term by treatment with benzodiazepines or anticholinergic preparations, and temporary success has been claimed for conditioning therapy, ${ }^{10}$ biofeedback, ${ }^{11}$ and psychoanalysis, ${ }^{12}$ the latter in a patient whose painful cramps were believed to constitute a compensatory mechanism for inadequate penile erection. No long term improvement, however, has ever been achieved by these techniques. In view of this, the last resort is likely to be that advocated by an eminent senior colleague recently asked for advice on the treatment of a Department of Health and Social Security clerk with writer's cramp in the right hand. His reply "Tell him to use the other hand" may be regarded as therapeutic nihilism of the worst kind, although Gowers records a gratifying response to the same approach. ${ }^{9}$ His patient, a Government clerk afflicted with writer's cramp on the right, successfully switched to writing with his left hand, continued to work for 12 years, and retired on a pension. Plus fa change.

P HUdGSON

Consultant and Senior Lecturer in Neurology,

Regional Neurological Centre,

Newcastle General Hospital,

Newcastle upon Tyne NE4 6BE

${ }^{1}$ Foster JB. Putting on the agony. . . World Medicine 1977;12, 19:26-7. 2 Sheehy MP, Marsden CD. Writers' cramp-a focal dystonia. Brain $1982 ; 105: 461-80$.

${ }^{3}$ Gowers WR. A manual of diseases of the nervous system. Vol II. 1st ed. London: $J$ and A Churchill, 1886-8.

4 Zeman W, Dyken P. Dystonia musculorum deformans. In: Vinken PJ, Bruyn GW, eds. Handbook of clinical neurology. Vol 6. Amsterdam: North Holland, 1968:517-43.

${ }^{5}$ Babinski J. Spasme facial post-encéphalitique. Rev Neurol (Paris) 1921; 28:462-8.

6 Barre J-A. La crampe des écrivains, maladie organique, ses formes, ses causes. Rev Neurol (Paris) 1952;86:703.

7 Meares R. An association of spasmodic torticollis and writer's cramp. Br $\mathcal{F}$ Psychiatry 1971;119:441-2. 
${ }^{8}$ Marsden CD. Dystonia: the spectrum of disease. In: Yahr MD, ed. The basal ganglia. New York: Raven Press, 1976.

${ }^{9}$ Gowers WR. A manual of diseases of the nervous system. Vol II. 2nd ed. London: J and A Churchill, 1892-3.

9a Anonymous. Writers' cramp. Lancet 1982 ;ii :969.

10 Liversedge LA. Writer's cramp and the conditioned reflex. In: Garland H, ed. Scientific aspects of neurology. Edinburgh: E and S Livingstone, 1961.

1 Bindman E, Tibbetts RW. Writer's cramp-a rational approach to treatment? Br ₹ Psychiatry 1977;131:143-8.

12 Brun R. Psychoanalytische Behandlung und Heilungeines Schreibkrampfes verbuden mit steifigkeit und Paraesthesien in den Armen. Acta Psychotherapeutica et Psychosomatica (Basel) 1964;12:382-90.

\section{Crisis in rheumatology manpower}

Most of the current trainees in rheumatology were encouraged to enter what was thought to be an expanding specialty. They now face the prospect of their planned career evaporating before their eyes. There are 95 senior registrar posts, yet fewer than 10 consultants seem likely to be appointed each year in the immediate future-so that either training will last, on average, 10 years or many trained clinical rheumatologists will be forced to leave rheumatology altogether. They face this prospect at a time when moving sideways into another branch of medicine is impossible. If they leave rheumatology they will have to start training from scratch for another career.

The factors which have combined to produce this crisis were not foreseen. The most important has been the failure of the Department of Health and Social Security and regional health authorities to fund the planned expansion of consultant posts in both rheumatology and rehabilitation. In theory expansion continues-over 20 posts have received manpower approval in the past two years-but in practice most remain unadvertised owing to lack of funding. In the light of current government attitudes little change seems likely.

A contributory factor has been the expansion of training posts funded outside the NHS-the research appointments financed partly by "soft money" from charitable or scientific bodies such as the Arthritis and Rheumatism Council and often by the pharmaceutical industry in support of work on a specific product. Though in theory many of these posts do not qualify for career training recognition by the Joint Committee on Higher Medical Training, in practice the incumbents compete in the same career market. Furthermore, a new trend has been apparent at several recent consultant appointments where moves have been made to combine the commitments of general medicine with those of rheumatology. General physicians should be concerned about the threat to their own specialist practice of internal medicine which this trend poses. Rheumatologists, most of whom have not had higher training in general medicine (only 13 recognised training posts exist which are said to combine both specialties), can no more provide comprehensive and up to date skill in internal medicine than can general physicians in rheumatology.

Though some competition for consultant appointments may be healthy, no one can justify the waste of manpower, training facilities, and frustration that will flow from current arrange- ments. Four steps must be considered by the specialty if it is to make reasonable provisions for the immediate future and $\frac{}{c}$ honour its commitment to current trainees. Firstly, though $\bar{\Omega}$ senior registrars complete their training in four years they $\overline{\bar{J}}$ should be allowed to remain in post for up to six years before गु their future in rheumatology is reviewed. This would allow $\$$ extra time for current trainees to obtain consultant posts $\stackrel{\text { T⿱ }}{2}$ without undue pressure to abandon their career. It would also help direct the competition to the start of training, when alternatives should be considered, rather than at the end. Secondly, every pressure should be brought to bear on regional health authorities to fund approved consultant posts. At the same $\frac{\bar{\sigma}}{\bar{\phi}}$ time current moves in a few areas to allow consultant rheuma- $\varnothing$ tology posts to lapse must be strenuously resisted. (Trainees are alarmed to learn that there may even be pressure in some $\vec{\circ}$ hospitals to sacrifice existing consultant posts for apparent short term benefit.) Thirdly, the balance between training posts ${ }_{\sigma}^{\omega}$ and projected consultant vacancies must be improved in the음 medium term. This implies halving the current senior registrar

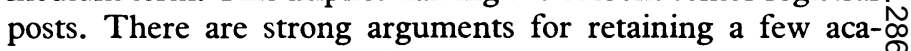
demically orientated posts funded by research bodies, but most $\%$ of those supported by the pharmaceutical industry and some within the NHS would best be abandoned (if necessary by withdrawing training recognition). In some instances twoo training posts might be replaced by one consultant post-to응 the advantage of both the service and budget. In filling those $\vec{\bullet}$ training posts to be retained preference should be given to those already committed to rheumatology (who may have spent some time in research based or locum posts), rather than more junior applicants.

Fourthly, and in the longer term, the profession will surely $\vec{\oplus}$ have to adopt the principle that selection for higher training inc any specialty should be followed by appointment to consultanto when satisfactory training is completed. This principle is contained in the Short report, ${ }^{1}$ but fear of indiscriminate conversion of training to consultant posts with inadequate funding has caused some hospital staff to be sceptical. The set $\stackrel{\mathbb{Q}}{\varrho}$ up in rheumatology, arising during the course of an agreed $\vec{O}$ expansion stimulated by the recognised needs of patients 3 suffering from rheumatic diseases, provides an opportunity to alter the relation between consultant and training posts rapidly.

The proposals outlined here appear to be the only counter to the growing disillusionment among trainees, not only in rheumatology but also in other specialties. This dis - . illusionment may itself be one of the greatest threats to the continued provision of good health care in Britain.

\section{JOHN R KIRWAN}

Medical Research Council Research Fellow and

Senior Registrar in Rheumatology and Rehabilitation,

London Hospital and Medical College,

London E1 2AD; and

Trainees' Representative,

Education, Training, and Accreditation Subcommittee of the British Association for Rheumatology and Rehabilitation

${ }^{1}$ Social Services Committee. Fourth report. Medical education with specia $\bar{Q}$ reference to the number of doctors and the career structure in hospitals London: HMSO, 1981. (Short report.) 